\title{
MicroRNA: A New Player for Cancer Chemoprevention
}

Yaguang $\mathbf{X i}^{*}$

University of South Alabama, Mitchell Cancer Institute, USA

\section{Keywords: MicroRNA; Chemoprevention; Metastasis}

In 2012, a total of 1,638,910 new cases and 577,190 deaths from cancer are projected to occur in the United States [1]. From 2004 to 2008, the overall cancer death rate was decreased by $1.8 \%$ in men versus $1.6 \%$ in women yearly, which may result from the successful implementation of early detection, treatment, and prevention methods [1]. Although its potential has not yet been fully realized, chemoprevention by using pharmaceuticals (e.g. anti-inflammatory drugs) to retard or reverse the process of carcinogenesis and progression of cancer has been recognized to benefit individuals with precancerous lesions or with genetic susceptibility to cancer [2-4]. The concept of chemoprevention encompasses all stages of disease progression including the prevention of tumor initiation through DNA repair, detoxification, free-radical scavenging, and carcinogen metabolism; prevention of tumor promotion by inhibiting proliferation or inducing differentiation or apoptosis; and the inhibition of tumor progression by suppressing tumor cell invasion and metastasis [5].

Tumor metastasis is a hallmark of malignant disease that is often responsible for chemotherapy failure and death of the patient. It was estimated that only $6 \%$ of breast cancer patients have detectable metastatic disease at the time of diagnosis and surgery [6]. Thus, prevention of tumor cell invasion and metastasis represents a largely unexplored target for chemoprevention in patients with malignant disease who are at risk of disease progression. Due to poor understanding of the mechanistic basis that accounts for this complex biological process, there are very few therapeutic and preventive drugs have been discovered that can be successfully used to treat cancer patients with metastasis in clinic.

Nonsteroidal Anti-Inflammatory Drugs (NSAIDs) are a chemically diverse family of drugs commonly used to treat a variety of inflammatory conditions and pain associated with arthritis. The long-term use of NSAIDs has been shown to significantly reduce the incidence and risk of death from colorectal and other forms of cancer [7]. Sulindac, in particular, has been shown to display strong efficacy for the treatment of precancerous lesions in patients with Familial Adenomatous Polyposis (FAP) in which treatment can suppress adenoma size and number by as much as $60-70 \%$ [8]. These observations are consistent with a large number of preclinical studies that have shown the ability of sulindac and other NSAIDs to inhibit tumorigenesis and tumor progression in various experimental animal models [9-12]. For example, Moon et al. found that sulindac was able to induce the expression of thrombospondin-1 (TSP-1) and early growth response gene-1(Egr-1) by using the Min mouse model, both of which were considered to play a role in the suppression of tumor cell invasion [13]. The study by Kundu et al. showed that celecoxib (COX-2 inhibitor), SC560 (COX-1 inhibitor), and the non-selective COX-1/2 inhibitor (indomethacin), could inhibit not only tumor cell growth, but also metastasis in vivo [14]. A recent LANCET publication reported that daily use of aspirin could reduce the risk of death from tumor metastasis by up to $48 \%$ based on meta-analyses of a large number of randomized controlled clinical trials [15]. Therefore, NSAIDs have a potential to prevent tumor metastasis and disease progression and the use of NSAIDs should be a viable option for cancer patients with advanced diseases.
MicroRNAs (miRNAs) are naturally occurring, single-stranded, and non-coding sequences of small RNAs that bind to 3'-UTR of target genes to repress their expression at the post-transcriptional and translational levels $[16,17]$. Nearly $30 \%$ of all human genes are regulated by miRNAs in which each is capable of mediating the expression of several hundred cognate messenger RNA targets simultaneously [18]. Approximately 2,000 human miRNAs have been characterized that are involved in many biological processes including apoptosis, proliferation, differentiation, tumorigenesis, and metastasis [19-22]. We recently reported in ONCOGENE that sulindac sulfide (SS) can inhibit tumor cell invasion by a distinct mechanism from its COX inhibitory activity [23]. By using microarray analysis, we found that SS treatment could alter the expression of 132 miRNAs (17 up and 115 down) in human colon cancer HCT116 cells at sub-toxic concentrations. Several of these miRNAs are of particular interest to us, such as miR-10b, -17 , -21 , and -9 , because they have been previously reported to promote tumor metastasis and invasion [24-30]. In addition, we demonstrated that inhibition of NF- $\kappa B$ by SS is an important mechanism attributing to suppression of these oncogenic miRNAs [23]. As the inhibitory effect of SS on tumor cell invasion was proved to be associated with dramatic changes in miRNA expression, we concluded that miRNAs are involved in the anti-metastatic activity of sulindac [23].

Although miRNA has been involved in the pathogenesis of variable human cancer types and are significantly associated with the clinicopathological parameters and treatment responses, its important roles in cancer chemoprevention have not yet been well studied. Given that miRNAs are recognized as the master gene expression regulators and the changes of their multiple target genes are tightly associated with almost all cellular events, miRNAs may account for the mechanistic basis of NSAIDs' complex pleiotropic antineoplastic activities. Therefore, studying miRNA in cancer chemoprevention is of novelty and significance for discovering and developing safer and more efficacious antineoplastic drugs in the future.

\section{Acknowledgment}

This study was supported by the $\mathrm{NIH} / \mathrm{NCl}$ grant $1 \mathrm{R} 21 \mathrm{CA} 160280-01 \mathrm{~A} 1$ (Xi).

\section{References}

1. Siegel R, Naishadham D, Jemal A (2012) Cancer statistics, 2012. CA: a cancer journal for clinicians 62: 10-29.

2. Whitt JD, Li N, Tinsley HN, Chen X, Zhang W, et al. (2012) A novel sulindac derivative that potently suppresses colon tumor cell growth by inhibiting cGMP

*Corresponding author: Yaguang Xi, Assistant Professor of Oncologic Sciences, Mitchell Cancer Institute, University of South Alabama, 1660 Springhill Ave., Mobile AL 36604, Tel: (251) 445 9857; Fax: (251) 460 6994; E-mail: xi@usouthal.edu

Received January 04, 2013; Accepted January 04, 2013; Published January 07 2013

Citation: Xi Y (2013) MicroRNA: A New Player for Cancer Chemoprevention. J Integr Oncol 1:105. doi:10.4172/2329-6771.1000105

Copyright: (c) 2013 Xi Y. This is an open-access article distributed under the terms of the Creative Commons Attribution License, which permits unrestricted use, distribution, and reproduction in any medium, provided the original author and source are credited. 
phosphodiesterase and $\beta$-catenin transcriptional activity. Cancer Prev Res (Phila) 5: 822-833.

3. Kelloff GJ (2000) Perspectives on cancer chemoprevention research and drug development. Adv Cancer Res 78: 199-334.

4. Wattenberg LW (1985) Chemoprevention of cancer. Cancer Res 45: 1-8.

5. Hursting SD, Slaga TJ, Fischer SM, DiGiovanni J, Phang JM (1999) Mechanism-based cancer prevention approaches: targets, examples, and the use of transgenic mice. J Nat Cancer Inst 91: 215-225.

6. Steeg PS (2006) Tumor metastasis: mechanistic insights and clinical challenges. Nat Med 12: 895-904.

7. Smalley W, Ray WA, Daugherty J, Griffin MR (1999) Use of nonsteroidal antiinflammatory drugs and incidence of colorectal cancer: a population-based study. Arch Intern Med 159: 161-166.

8. Giardiello FM, Hamilton SR, Krush AJ, Piantadosi S, Hylind LM, et al. (1993) Treatment of colonic and rectal adenomas with sulindac in familial adenomatous polyposis. N Engl J Med 328: 1313-1316.

9. Beazer-Barclay Y, Levy DB, Moser AR, Dove WF, Hamilton SR, et al. (1996) Sulindac suppresses tumorigenesis in the Min mouse. Carcinogenesis 17 $1757-1760$.

10. Mahmoud NN, Boolbol SK, Dannenberg AJ, Mestre JR, Bilinski RT, et al. (1998) The sulfide metabolite of sulindac prevents tumors and restores enterocyte apoptosis in a murine model of familial adenomatous polyposis. Carcinogenesis 19: 87-91.

11. Piazza GA, Alberts DS, Hixson LJ, Paranka NS, Li H, et al. (1997) Sulindac sulfone inhibits azoxymethane-induced colon carcinogenesis in rats without reducing prostaglandin levels. Cancer Res 57: 2909-2915.

12. Thompson HJ, Jiang C, Lu J, Mehta RG, Piazza GA, et al. (1997) Sulfone metabolite of sulindac inhibits mammary carcinogenesis. Cancer Res 57: 267271.

13. Moon Y, Bottone FG Jr, McEntee MF, Eling TE (2005) Suppression of tumor cell invasion by cyclooxygenase inhibitors is mediated by thrombospondin-1 via the early growth response gene Egr-1. Mol Cancer Ther 4: 1551-1558.

14. Kundu N, Fulton AM (2002) Selective cyclooxygenase (COX)-1 or COX2 inhibitors control metastatic disease in a murine model of breast cancer. Cancer Res 62: 2343-2346.

15. Rothwell PM, Wilson M, Price JF, Belch JF, Meade TW, et al. (2012) Effect of daily aspirin on risk of cancer metastasis: a study of incident cancers during randomised controlled trials. Lancet 379: 1591-1601.

16. Bartel DP (2004) MicroRNAs: genomics, biogenesis, mechanism, and function Cell 116: 281-297.

17. Ambros $V$ (2004) The functions of animal microRNAs. Nature 431: 350-355.

18. Lewis BP, Burge CB, Bartel DP (2005) Conserved seed pairing, often flanked by adenosines, indicates that thousands of human genes are microRNA targets. Cell 120: 15-20.

19. Lee YS, Kim HK, Chung S, Kim KS, Dutta A (2005) Depletion of human microRNA miR-125b reveals that it is critical for the proliferation of differentiated cells but not for the down-regulation of putative targets during differentiation. J Biol Chem 280: 16635-16641.

20. Takamizawa J, Konishi H, Yanagisawa K, Tomida S, Osada H, et al. (2004) Reduced expression of the let-7 microRNAs in human lung cancers in association with shortened postoperative survival. Cancer Res 64: 3753-3756.

21. Carmell MA, Xuan Z, Zhang MQ, Hannon GJ (2002) The Argonaute family: tentacles that reach into RNAi, developmental control, stem cell maintenance, and tumorigenesis. Genes Dev 16: 2733-2742.

22. Karube Y, Tanaka H, Osada H, Tomida S, Tatematsu Y, et al. (2005) Reduced expression of Dicer associated with poor prognosis in lung cancer patients. Cancer Sci 96: 111-115.

23. Li X, Gao L, Cui Q, Gary BD, Dyess DL, et al. (2012) Sulindac inhibits tumor cell invasion by suppressing NF-KB-mediated transcription of microRNAs. Oncogene 31: 4979-4986.

24. Yu Z, Willmarth NE, Zhou J, Katiyar S, Wang M, et al. (2010) microRNA 17/20 inhibits cellular invasion and tumor metastasis in breast cancer by heterotypic signaling. Proc Natl Acad Sci U S A 107: 8231-8236.
25. Huang GL, Zhang XH, Guo GL, Huang KT, Yang KY, et al. (2009) Clinical significance of miR-21 expression in breast cancer: SYBR-Green I-based realtime RT-PCR study of invasive ductal carcinoma. Oncol Rep 21: 673-679.

26. Ma L, Reinhardt F, Pan E, Soutschek J, Bhat B, et al. (2010) Therapeutic silencing of miR-10b inhibits metastasis in a mouse mammary tumor model. Nat Biotechnol 28: 341-347.

27. Ma L, Teruya-Feldstein J, Weinberg RA (2007) Tumour invasion and metastasis initiated by microRNA-10b in breast cancer. Nature 449: 682-688.

28. Ma L, Young J, Prabhala H, Pan E, Mestdagh P, et al. (2010) miR-9, a MYC/ MYCN-activated microRNA, regulates E-cadherin and cancer metastasis. Nat Cell Biol 12: 247-256.

29. Song B, Wang C, Liu J, Wang X, Lv L, et al. (2010) MicroRNA-21 regulates breast cancer invasion partly by targeting tissue inhibitor of metalloproteinase 3 expression. J Exp Clin Cancer Res 29: 29.

30. Zhu S, Wu H, Wu F, Nie D, Sheng S, et al. (2008) MicroRNA-21 targets tumor suppressor genes in invasion and metastasis. Cell Res 18: 350-359. 